\title{
PadimPet: uma solução para incentivar o apadrinhamento de animais
}

\author{
Raíssa Lemos \\ Marcelo Martins \\ Rafaella Fernandes \\ Filipe Francisco Andreia Libório (Líder) \\ Universidade Federal do Ceará - Campus de Quixadá
}

[rahbarros, chescoo, andreia.ufc]@gmail.com, [mmartins, rafaellafernandes]@alu.ufc.br

\begin{abstract}
RESUMO
O abandono de animais é um problema presente em vários países e de difícil solução. Dentre alternativas possíveis para contornar este problema, o apadrinhamento surge como opção para quem não pode criar animal em casa. Este projeto parte de uma pesquisa realizada através de um formulário online com 91 pessoas, realizando uma análise das respostas para identificar pontos que incentivem o apadrinhamento. Com base nas informações obtidas, foi proposta uma solução que combina aplicativo e sistema embarcado para promover a interação entre abrigo e padrinho, além do acompanhamento dos animais apadrinhados.
\end{abstract}

\section{PALAVRAS-CHAVE}

abandono de animais, apadrinhamento, abrigo, sistema embarcado

\section{INTRODUÇÃO}

De acordo com a Organização Mundial de Saúde (OMS), no Brasil temos pelo menos 30 milhões de animais abandonados, divididos em 20 milhões de cachorros e 10 milhões de gatos [1]. Esse problema é uma questão de saúde pública e está presente em diversas regiões do nosso país.

A Lei $n^{\circ}$ 9.605/98 (Lei de Crimes Ambientais) considera o abandono de animais como uma forma de agressão. Em seu artigo 32, ela prevê detenção de 3 meses a 1 ano e multa para quem pratica atos de abuso ou maus-tratos, fere ou mutila animais [2].

Iniciativas com o intuito de promover a conscientização sobre maus-tratos e o incentivo à adoção de animais estão em expansão. Em Curitiba, um projeto de lei (PL) prevê o incentivo à adoção de animais de rua. A PL número 102 de 2018 propõe que estabelecimentos que trabalhem com animais, como pet shops e ONGs, exponham em suas sedes cartazes de conscientização, além

\footnotetext{
Permission to reproduce or distribute, in whole or in part, material extracted from this work, verbatim, adapted or remixed, as well as the creation or production from the content of such work, is granted without fee for non-commercial use, provided that the original work is properly credited.

IHC 2019 - Competição de Design, Outubro 21-25, 2019, Vitória, Brasil. In Anais Estendidos do XVIII Simpósio Brasileiro sobre Fatores Humanos em Sistemas Computacionais. Porto Alegre: SBC.

(C) 2019 by the author(s), in accordance with the terms of the Creative Commons Attribution-NonCommercial 4.0 International Public License (CC BY-NC 4.0).
}

do incentivo para que as lojas de pets realizem campanhas de adoção. A ideia destas campanhas é transmitir a informação para que as pessoas possam estar cientes e passem a aderir ao cadastramento dos animais, por meio de um programa realizado pela Prefeitura de Curitiba, além de visar o incentivo da adoção responsável [3].

Através de pesquisa de campo realizada, foi possível verificar que existem pessoas interessadas em adotar, mas inviabilizadas por motivos pessoais ou financeiros. $\mathrm{O}$ apadrinhamento é uma alternativa para melhorar a qualidade de vida dos animais de abrigos que visa o aumento de doações referentes à alimentação, medicação e serviço voluntário em atividades coletivas [4].

Buscando-se estimular o apadrinhamento através da aproximação entre pessoas e instituições de abrigo, foi projetada uma combinação de aplicativo e sistema embarcado para juntos formarem um sistema capaz de informar sobre as necessidades do abrigo, além de permitir o acompanhamento dos animais apadrinhados.

A solução desenvolvida consiste na combinação entre um aplicativo dividido em duas vertentes (abrigos e padrinhos) e um dispenser com hardware embarcado que armazena e despeja os alimentos dos animais. De modo geral, a solução apresenta informações em tempo real sobre o animal e emite notificações sobre controle do estoque e doações online, além de transparência em relação ao fluxo de doações.

\section{METODOLOGIA}

A organização metodológica do trabalho se utiliza das etapas gerais do Processo de Design Digital Disruptivo ( $\mathrm{PD}_{3}$ ) [5]. O $\mathrm{PD}_{3}$ agrega duas abordagens metodológicas clássicas de processos de design. A primeira organiza o processo de design em cinco etapas, que no $\mathrm{PD}_{3}$ denominam-se Sprints: (1) Definição do Problema, (2) Análise de Contexto, (3) Modelo Conceitual, (4) Projeto Detalhado, (5) Produção/Divulgação. A segunda abordagem metodológica clássica organiza o processo de design em três etapas: análise, síntese e avaliação [5]. Assim, no $\mathrm{PD}_{3}$ realizam-se análise-sínteseavaliação cinco vezes, de forma iterativa e incremental, uma vez para cada Sprint. Na Sprint 1, Definição do Problema, o tema geral 
de abandono de animais foi analisado em literatura, chegando-se ao problema específico de apadrinhamento de animais. Adicionalmente, o tema foi avaliado através de conversas exploratórias, não estruturadas, com três pessoas que relataram ter dificuldade de oferecer lar temporário e preferirem o apadrinhamento. Como resultado desta etapa, temos o "briefing" de definição do problema [6].

Na Sprint 2, Análise de Contexto, foi analisada a realidade de apadrinhamento nos abrigos e a opinião das pessoas que se preocupam com a causa de abandono de animais, sobre apadrinhamento. Foram realizadas duas pesquisas online, sendo a primeira para pessoas em geral com o objetivo de explorar o histórico de adoções, apadrinhamentos ou interesse pela causa, obtendo um total de 91 respostas. A segunda foi destinada a abrigos para se obter informações sobre frequência de doações, estrutura do local de alimentação dos animais, comunicação os padrinhos e inclusão de tecnologia para ajudar no abrigo. A análise de dados foi sintetizada na forma de personas e cenários de uso. A avaliação do contexto foi feita pela análise qualitativa e quantitativa das respostas dos dois questionários.

Na Sprint 3, elabora-se um modelo conceitual do projeto. Foram definidas a identidade visual do projeto, as funcionalidades e a navegação das duas versões do aplicativo (abrigo e padrinhos), bem como a prototipação de telas. Adicionalmente, foi projetado um dispenser inteligente responsável por armazenar e despejar o alimento. Foi definida sua arquitetura, funcionamento, sensores e forma de comunicação com o aplicativo. $\mathrm{O}$ detalhe desse projeto pode ser visto no PDP - Proposta de Desenvolvimento Projetual [7]. Após análise de alternativas, os detalhes do desenvolvimento foram definidos considerando a disponibilidade do uso de tecnologia por parte dos abrigos e dos padrinhos, além da escolha de componentes eletrônicos aplicáveis. Visando a avaliação da ideia, foi desenvolvido um protótipo do dispenser, o qual foi instalado na área de convivência da Universidade Federal do Ceará - Campus Quixadá onde se comportou como alimentador para os cachorros que circulam diariamente pelas redondezas. A instalação do dispenser inteligente na universidade foi um método utilizado como prova de conceito e para justificar a viabilidade. As duas últimas sprints do PD3, Projeto Completo e Produção/Divulgação, são etapas futuras. Entretanto, como requisito da competição do IHC, foi antecipada uma peça de divulgação, produzindo-se um vídeo ilustrativo da ideia [8].

\section{JUSTIFICATIVA}

A aplicação do formulário direcionado ao público resultou na coleta de dados de 91 pessoas. Conforme os dados coletados, $26,1 \%$ disseram ter dúvidas se adotariam ou não, por vários motivos: ter alergia a pelos de animais, viajar com frequência e não ter com quem deixar o animal, não ter espaço em casa, não ter tempo, já ter outro animal e não ter espaço para mais um, dentre outros. Teve ainda o caso de um participante que disse gostar da causa de defender os animais, mas "Acho que não tenho muita habilidade pra cuidar". Estes pontos reforçam a ideia do apadrinhamento como uma alternativa, pois é uma forma de poder ajudar mesmo com essas questões apresentadas. Além disso, constatou-se que $85,7 \%$ das pessoas nunca apadrinharam, enquanto que $69,2 \%$ das pessoas estariam dispostas a apadrinhar um animal. Isto é um indicativo de que a ideia do apadrinhamento é bem aceita pelas pessoas, mas que ao mesmo tempo aparentemente é pouco difundida. Além disso, $73,9 \%$ disseram que no caso de apadrinharem, eles gostariam de ser avisados quando faltasse comida no abrigo.

Já o formulário direcionado aos abrigos resultou na coleta de dados de 6 abrigos e revelou que três deles não possuem padrinhos para os animais. Apesar disto, notou-se que todos recebem doações de comidas, medicamentos ou dinheiro. Dois deles recebem mensalmente, dois semanalmente, um diariamente, e um apenas quando as pessoas se comovem a ajudar. A necessidade de receber doações, aliada à informação de que existem muitas pessoas com desejo de ajudar os animais de rua mas que não teriam condições de levar para sua casa, reforça a proposta de apadrinhamento. Aos 3 abrigos com padrinhos, perguntou-se como é feito o controle das doações. Um deles disse que espera os padrinhos avisarem e enviarem os comprovantes. Outro disse que " $O$ padrinho se responsabiliza pelos custos do animal, então toda necessidade é solicitada e o padrinho ajuda.". O terceiro disse que apenas "Anotamos o nome do animal e o que foi recebido, por quem e quando". Quando perguntamos se pensam em como a tecnologia digital poderia ajudar nesse processo, dois abrigos disseram que usam redes sociais (Facebook e Instagram) para pedir ajuda, três disseram que poderiam ajudar, um deles sugeriu ser via aplicativo, e um deles não havia pensado sobre isso.

Notou-se, portanto, que os abrigos vivem de doações e precisam se comunicar com os doadores, padrinhos ou não. Estas são demandas que reforçam a ideia de uma solução que promova a comunicação entre padrinhos e abrigos. Além disso, percebemos a dificuldade do controle de estoque dos abrigos, justificando assim a ideia do uso de sensores avisando em tempo real sobre a quantidade de ração consumida.

\section{SOLUÇÃO PROPOSTA}

A proposta consiste de (i) um aplicativo que permite a interação entre pessoas e abrigos (Figura 1), e (ii) um dispenser de ração (Figura 2) contendo um dispositivo embarcado que atuará no controle em tempo real da ração, enviando informações para o aplicativo.

\subsection{APLICATIVO PadimPet}

O PadimPet consiste de dois módulos: um destinado aos abrigos e outro aos padrinhos. Eles se interligam com a troca de informações necessárias e em tempo real sobre a quantidade de ração consumida. 
O módulo dos abrigos permite o cadastro dos animais apadrinhados e contém informações como quantidade de ração necessária por dia, frequência e hora com que o animal come, registro de uso de medicamentos, aplicação de vacinas e vermífugos, idade, raça, dentre outros. Também possui funcionalidade de cadastrar os padrinhos. Além disso, podem ser cadastrados animais resgatados para que fiquem à disposição para apadrinhamento.

O módulo destinado aos padrinhos, por sua vez, permite a busca por um abrigo específico e também oferece sugestões de abrigos próximos à localização do usuário. Através do aplicativo é possível apadrinhar um animal e acompanhar sua alimentação e quesitos relacionados ao seu estado de saúde (como vacinação e vermífugo), além de facilitar o controle online de doações.

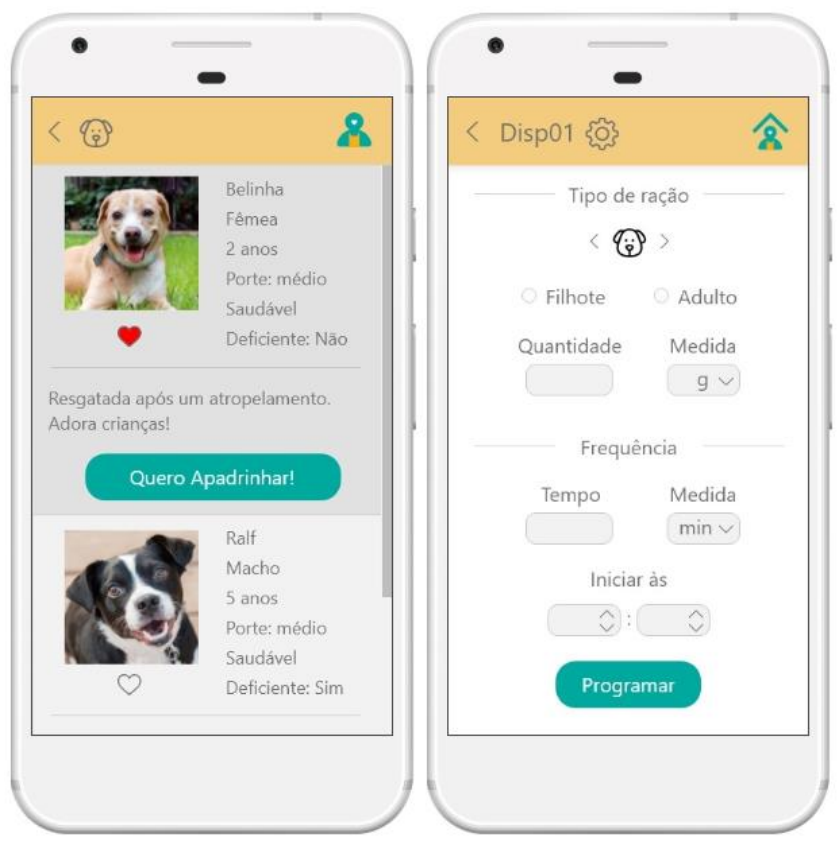

Figura 1 - Telas do Aplicativo PadimPet

A Figura 1 mostra o protótipo PadimPet. Do lado esquerdo, pode ser vista a tela de escolha de animais para apadrinhar. Do lado direito, pode ser vista a tela de configuração do dispenser a ser usada pelo responsável do abrigo para programar a hora e a frequência com que deve ser despejada a ração. A solução prevê que o abrigo tenha inúmeros dispensers. O protótipo interativo pode ser acessado de forma online [9-10].

\subsection{O DISPENSER INTELIGENTE}

Foi desenvolvido um protótipo de sistema de alimentação inteligente para os abrigos, ilustrado na Figura 2, o qual tem como principal funcionalidade o controle e automação do fornecimento de ração.

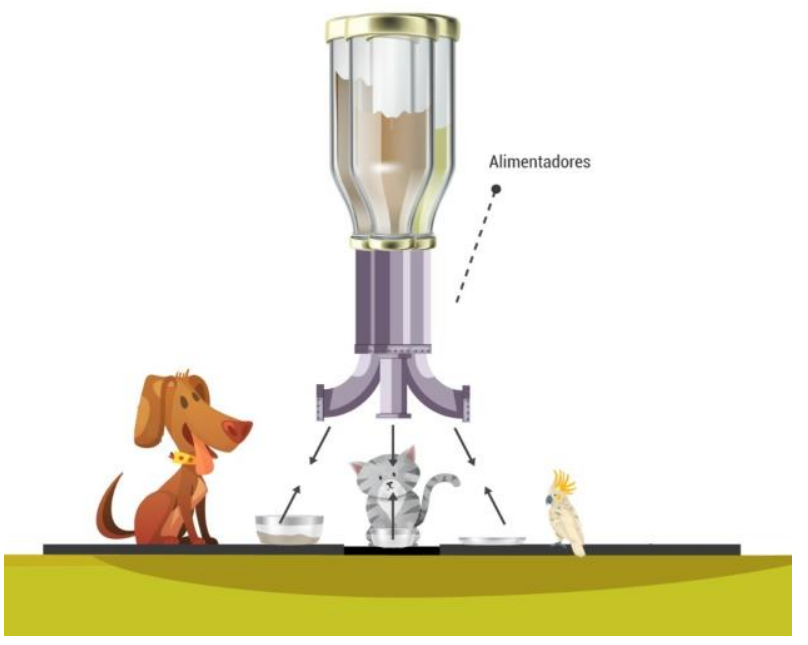

Figura 2 - Ilustração do Dispenser

O dispositivo funciona de maneira a permitir que os usuários tenham controle sobre a quantidade de ração e estado do dispositivo. O sistema irá monitorar as informações diárias com o auxílio de células de cargas que serão usadas como balança. Dessa forma, será possível liberar a ração de uma forma automatizada para a alimentação dos animais, através de um horário préprogramado ou através de comandos no aplicativo.

Para a concepção do projeto foram feitos dois projetos, o do dispenser e o da arquitetura de componentes para o mesmo. O projeto do protótipo do dispenser consiste em um dosador de rosca impulsionado por um motor de passos para que seja realizado o despejamento do alimento. Embutido ao dispenser existem componentes de sensoriamento do peso para obtenção dos dados que serão enviados ao aplicativo. As peças necessárias para a formação do dispenser projetado são oriundas de modelação 3D através da plataforma Tinkercad [11], visando moldar de forma mais específica aos objetivos de aplicação. A figura 3 apresenta a modelagem:

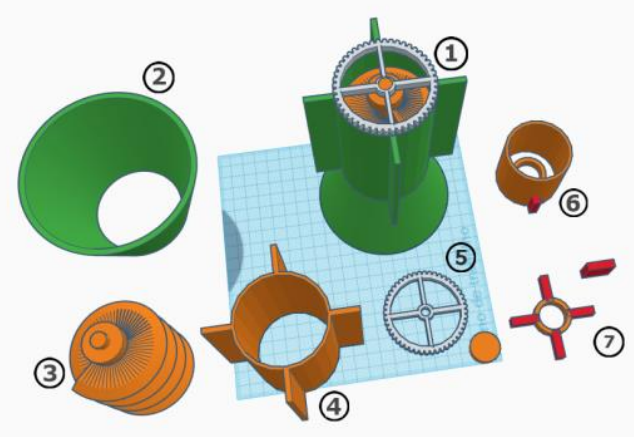

Figura 3 - Modelagem do dispenser na plataforma Tinkercad 
Os componentes (1) e (2) juntos formam o modelo do dispenser, sendo o primeiro o módulo mecânico do sistema e o segundo o módulo por onde será despejado e armazenado o alimento. A aplicação do sistema será em abrigos com quantidades diferentes de animais que irão utilizar o alimentador, portanto o projeto conta com a implementação de uma rosca dosadora (3) devido a dois aspectos: precisão e facilidade. A dosagem da rosca, alocada de forma vertical em (1) através das peças de suporte (6) e (7) e revestida pela peça (4) do dispenser, fomenta a precisão e assim assegura a pesagem certa. Além disso, o processo de higienização da rosca se torna fácil já que há praticidade para remover e alocar ao dispenser. A rosca se atrela à engrenagem (5) através do rolamento (7) para que seja possível a movimentação giratória. A engrenagem citada se atrela a outra engrenagem externa que gira pelo impulsionamento de um motor de passo + driver que serão unidos ao dispenser, assim realizando o movimento desejado da rosca dosadora.

Para o projeto da arquitetura de componentes do sistema, foram selecionados dispositivos eletrônicos de baixo custo para que sua utilização e implementação no sistema fosse simples para a aplicação desejada. A figura 4 apresenta a arquitetura de componentes do sistema.

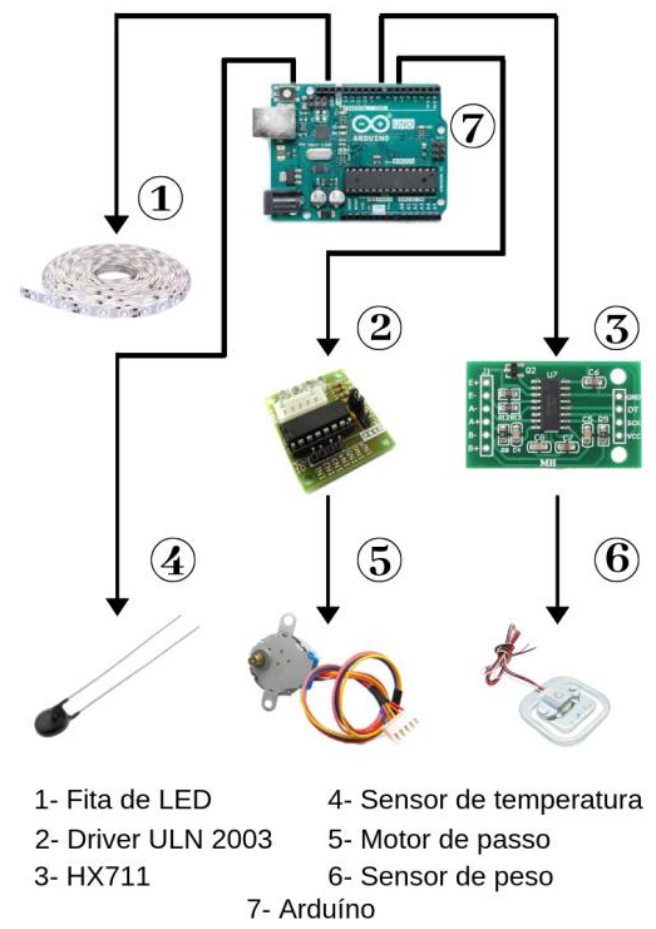

Figura 4 - Arquitetura de componentes

O protótipo desenvolvido é uma combinação entre recipiente eletrônico, sensores de temperatura e peso junto ao aplicativo PadimPet. A placa utilizada para o processamento das variáveis ambientais foi o Arduino Uno, um projeto de Open Hardware de fácil manuseio ideal para prototipação e validação de projetos [1213]. Sua funcionalidade no sistema embarcado é dividida nos módulos: Recipiente Eletrônico e Verificação da Ração Armazenada.

O dispenser inteligente contém um Recipiente Eletrônico atrelado ao local de alimentação. O Recipiente Eletrônico é responsável por armazenar e realizar o despejamento da comida em um reservatório acessível ao animal. Para isso será utilizado um motor de passos com caixa de redução, que já possui o conector ideal para conexão no módulo driver para motor de passo ULN2003. A tensão de operação do Motor de Passo 5V 28BYJ-48 é 5V, o que lhe permite trabalhar em conjunto com as principais placas de desenvolvimento do mercado [14]. Além disso, o motor de passos será utilizado em conjunto com um Driver ULN2003 que é capaz de controlar motores de passo do tipo unipolar que possuem saídas digitais que variam de 0 a 5V [15], e que será configurado considerando a relação entre quantidade de ração despejada e quantidade de passos dados pelo motor.

O módulo verificação da ração armazenada utilizará um sensor de peso/célula de carga que deve ser utilizado em conjunto com o módulo analógico digital de 24 bits HX711, ideal para células de carga para amplificação do sinal gerado pela célula. $\mathrm{O}$ sensor de peso é composto por uma meia-ponte resistiva, e quando aplicado um peso sobre o sensor, este gera uma tensão que é enviada ao microcontrolador [16]. Juntamente ao sensor, encontra-se o amplificador de instrumentação Hx711, que foi projetado com a finalidade de proporcionar a conversão de alterações de valor de resistência em sensores, como por exemplo, uma balança, em dados digitais. Esta conversão é possível através de um circuito AD de 24 bits presente no módulo [17]. Os sensores de peso existentes em balanças não possuem precisão em seus dados, por isso se faz necessário o uso de um módulo desenvolvimento especificamente para uso com sensores de peso. Sua comunicação com os microcontroladores se dá pelo padrão TTL 232, o qual possui facilidade de uso, estrutura descomplicada e desempenho estável para o envio de dados de peso da ração.

Para a medição da temperatura da comida, foi empregado um sensor de temperatura NTC $10 \mathrm{~K}$ Ohm, que possui uma alimentação de $5 \mathrm{~V}$, fornece uma saída analógica e possui uma faixa de operação que vai de $-55^{\circ} \mathrm{C} \mathrm{a}+125^{\circ} \mathrm{C}[18]$.

\subsection{CENÁRIO DE USO}

Sarah tem 20 anos e mora na cidade de Quixadá com seus dois cães e um gato de estimação que resgatou das ruas. Sempre foi empática com os animais e interessada em ajudar. Sendo novata na cidade, não sabia como poderia atuar no cenário local de abandonos. Por meio de divulgação, conheceu o aplicativo PadimPet. No seu primeiro contato descobriu o abrigo 4 Patas a apenas $2 \mathrm{~km}$ de sua casa. Navegando no PadimPet encontrou uma lista de cães e simpatizou com um filhote chamado Thomas. Por já ter animais de 
estimação em casa, Sarah considerou inviável adotá-lo, mas decidiu ajuda-lo. Sarah apadrinhou Thomas e, no mesmo instante, realizou uma doação online de 20 reais para medicamento do seu pet. No outro dia, indo para a faculdade, visitou o abrigo para ver seu novo afilhado. Atendida pela funcionária Helena, realizou uma doação de $3 \mathrm{~kg}$ de ração. Após a faculdade, via PadimPet, viu o registro de sua doação e um agradecimento do abrigo. Da parte do abrigo, ao receber a doação de ração, Helena registrou-a no aplicativo para que as informações de estoque fossem atualizadas, depositou a ração no alimentador automático de cães que estava programado para liberar comida a cada 6 horas. Dois dias depois, Sarah mostrou o aplicativo ao seu irmão Gabriel que morava na zona rural. Mesmo sem disponibilidade para visitar o abrigo, Gabriel ativou as notificações do PadimPet para ser alertado quando tivesse pouca ração no estoque do 4Patas. Além disso, conseguia visualizar os eventos de banho coletivos e vacinação, incentivando-o a fazer doações eventuais.

\section{VIABILIDADE}

Uma análise de viabilidade foi realizada através da implementação de um protótipo da solução. Uma das ameaças do projeto é o fato de ser multidisciplinar. Ele envolve conceitos de engenharia de software, design de interação, programação e sistemas embarcados. Um dos desafios foi uniformizar os conceitos e todos da equipe entenderem o funcionamento por completo da solução; a prototipação do dispenser e do aplicativo contribuiu bastante para isso. Além disso, a implementação do dispenser nos levou a discutir sobre vários aspectos de como seria fisicamente o dispenser e como ele iria se comunicar com o usuário e com o aplicativo, aspectos os quais não estavam bem definidos antes da prototipação. Identificamos a necessidade de termos elementos de feedback sobre o funcionamento e as marcações dos sensores não somente no aplicativo mas também no dispositivo físico (dispenser). Por exemplo, percebeu-se a necessidade de um marcador visual da quantidade de ração. Com isso surgiu a ideia de inserir uma fita de LED no repositório de ração para marcar o volume de ração existente. Além disso, sentimos necessidade de um display para marcar temperatura e peso da ração, data e hora, e poder retornar alguma mensagem ao usuário. Este display também seria útil caso a internet viesse a cair e a comunicação com o aplicativo fosse perdida. Outro ponto observado nessa avaliação foi identificar características do projeto físico do dispenser, como espaço para encaixar as peças do dispenser, barulho do motor de passos, etc. Já a comunicação entre dispenser e smartphone não foi avaliada pois utilizamos bluetooth e não a internet, como está previsto na proposta.

Quanto à viabilidade dos recursos tecnológicos disponíveis para a implementação do PadimPet vimos que eles são simples e de preço acessível. O dispenser inteligente consiste de um circuito eletrônico para receber e transmitir os comandos para liberar ração e monitorar a balança. Com a experiência da prototipação, percebeuse que a solução é viável. Os próximos passos são: (i) programar o aplicativo. Será utilizada a linguagem Java para o back-end e React para o front-end; (ii) imprimir um protótipo do dispenser utilizando uma impressora 3D e inserir os componentes eletrônicos embarcados; e (iii) realizar avaliação envolvendo usuários donos de abrigos e envolvendo a comunidade interessada em apadrinhar.

\section{REFERÊNCIAS}

[1] Bradespin, D. F. Posse responsável e bem-estar animal. In: I Encontro de Bioética e Bem-Estar Animal do Agreste Meridional Pernambucano. Garanhuns: Universidade Federal Rural de Pernambuco, 2006. p. 1-3. Acesso em 12 de junho de 2019.

[2] Brasil. Lei 9605, de 12 de fevereiro de 1998. Dispõe sobre as sanções administrativas e penais derivadas de condutas lesivas ao meio ambiente, e dá outras providências. Publicada no Diário Oficial da União em 13/02/1998.

[3] Xavier, Fernanda Unruh. Projeto de lei estimula incentivo a adoção de animais de rua em Curitiba. Conteúdo Online. Disponível em: < bit.ly/2ko64qj>. Acessado em 20 de junho de 2019.

[4] Dono, Cão sem. Apadrinhe um de nossos cãezinhos. Conteúdo online. Disponível em: 〈bit.ly/2lsW4fK〉. Acessado em 21 de junho de 2019.

[5] S. M. P., Tânia; T. M., Ingrid; A. F., Danilo; L. S., Andréia. O Processo de Design Digital: endereçando o desafio da multidisciplinaridade. In: IHC, 2018, Belém$\mathrm{Pa}$.

[6] Briefing PadimPet. Disponível em: https://drive.google.com/open?id=1YDDqFhaylV6bi_XyQYJudlb-scYCDmD-

[7] Proposta de Desenvolvimento Projetual (PDP) PadimPet. Disponível em https://drive.google.com/open?id=1E_iF4NTAE0b5c0zy-NpyEQ4zWZlpuYdO

[8] Vídeo ilustrativo do projeto PadimPet. Disponível em: https://youtu.be/c69PBsMxCx4

[9] Protótipo interativo do aplicativo PadimPet na versão Padrinho. Disponível em: https://marvelapp.com/77300i3/screen/58995726

[10] Protótipo interativo do aplicativo PadimPet na versão Abrigo. Disponível em: https://marvelapp.com/55292h3/screen/59002944

[11] J. F. Kelly, "3D Modelling and Printing with Tinkercad: Create and Print Your Own 3D Models", Pearson Education, 2014.

[12] A.R. de Souza et al., "The Arduino board: A Low-Cost Option for PC-Assisted Physics Experiments." Brazilian Journal of Teaching of Physics (Revista Brasileira de Ensino de Física), v. 33, n. 1, p. 01-05, 2011.

[13] F. A. Candelas et al., "Experiences on using Arduino for laboratory experiments of Automatic Control and Robotics" IFAC-PapersOnLine, v. 48, n. 29, p. 105 $110,2015$.

[14] Kiatronics. 28BYJ-48 - 5V Stepper Motor- DATASHEET 28BYJ-48.

[15] Studio, LC. ULN2003 MODULE - DATASHEET ULN2003. 2011.

[16] Al-Mutlaq, Sarah. Getting Started with Load Cells. Conteúdo Online, 2016 Disponível em < bit.ly/21OLa3V>

[17] Semiconductor, Avia. 24-Bit Analog-to-Digital Converter (ADC) for Weigh Scales. DATASHEET HX711. 2019.

[18] Cantherm. Pearl-Shaped Precision NTC Thermistor for Temperature Measurement. 2012 